\title{
A MONITORIA PARA ALUNOS SURDOS E CEGOS NO IFRN NATAL - CENTRAL: UMA PROPOSTA PARA O ENSINO ESCOLAR
}

\section{MONITOREO PARA ESTUDIANTES SORDOS Y CIEGOS EN EL IFRN NATAL - CENTRAL: UNA PROPUESTA PARA LA ENSEÑANZA ESCOLAR}

\section{THE MONITORING FOR DEAF AND BLIND STUDENTS AT IFRN NATAL - CENTRAL: A PROPOSAL FOR SCHOOL TEACHING}

\author{
Jéssica Eduarda dos Santos Silva ${ }^{1}$; Arnaldo André de Sousa Júnior ${ }^{2}$; Geraldo Felipe de Souza \\ Filho ${ }^{3}$; Vanessa Gosson Gadelhas de Freitas Fortes ${ }^{4}$
}

DOI: https://doi.org/10.31692/978-65-991061-3-2.59-73

\section{RESUMO}

A proposta de inclusão no Instituto Federal de Educação, Ciência e Tecnologia do Rio Grande do Norte - IFRN, Campus Natal Central - CNAT foi abraçada pelo Núcleo de Apoio às Pessoas com Necessidades Educativas Especiais - NAPNE que criou um projeto/pesquisa de monitoria aos alunos com necessidades específicas, procurando incluir e auxiliar esses alunos, tanto no aspecto de ensino-aprendizagem, quanto no aspecto social. A partir de um teste de sondagem foram observadas as dificuldades por parte dos discentes nas áreas de exatas principalmente em física. Logo, em 2018, foram convidados a participar da monitoria de alunos surdos do ensino médio, e foi aberta a proposta para alunos com necessidades especiais NEE de todo o campus Natal-Central, para o ensino de física. Em 2019, foi proposto manter o desenvolvimento do projeto de pesquisa na área de monitoria em que os alunos da Licenciatura em Física do campus, voluntários do NAPNE se prontificaram a atender os alunos tanto com surdez quanto com deficiência visual/cegueira, de forma individualizada ou em dupla, para então desenvolver o conhecimento sobre os fenômenos físicos da natureza, utilizando ferramentas de software, materiais adaptados e monitoria em auxílio às aulas regulares. Os resultados até o momento é a progressão dos conhecimentos dos discentes e a autonomia para a compreensão dos conceitos físicos associados a situação do cotidiano, além da prática de ensino pelos alunos de licenciatura em física. Esta pesquisa tem por objetivo abordar as principais dificuldades no ensinoaprendizagem de alunos com necessidades específicas, e lançar uma proposta para a rede de ensino, no auxílio desses alunos.

Palavras-Chave: Educação, Inclusão, Monitoria, Surdos, Cegos.

\section{RESUMEN}

La propuesta de inclusión en el Instituto Federal de Educación, Ciencia y Tecnología de Rio Grande do Norte - IFRN, Campus Natal Central - CNAT fue aceptada por el Centro de Apoyo a Personas con Necesidades Educativas Especiales - NAPNE, que creó un proyecto para monitorear a los estudiantes. con necesidades específicas, buscando incluir y ayudar a estos estudiantes, tanto en la enseñanza-aprendizaje como en los aspectos sociales. En una prueba de sondeo se observaron las dificultades de los estudiantes en las áreas exactas, principalmente en física. Pronto, en 2018, se invitó a estudiantes sordos de secundaria a participar en el monitoreo, y se abrió la propuesta para estudiantes con necesidades en todo el campus de Natal-Central

\footnotetext{
${ }^{1}$ Licencianda em física, IFRN - CNAT, jessicaeduardasantos@gmail.com

${ }^{2}$ Licenciando em física, IFRN - CNAT, junior-andre50@ hotmail.com

${ }^{3}$ Mestre em ensino de física, IFRN - CNAT, souza.geraldo@academico.ifrn.edu.br

${ }^{4}$ Doutora em educação, IFRN - CNAT, vanessa.fortes@ifrn.edu.br
} 
para educación física. En 2019, se propuso continuar con el desarrollo del proyecto de investigación en el área de monitoreo en el que los estudiantes de pregrado en física, voluntarios de NAPNE se ofrecieron como voluntarios para atender a estudiantes con sordera y ceguera, individualmente o en parejas, para luego desarrollar el conocimiento sobre los fenómenos físicos de la naturaleza, utilizando herramientas de software, materiales adaptados y monitoreo para asistir a las clases regulares. Los resultados hasta ahora son la progresión del conocimiento y la autonomía de los estudiantes para comprender los conceptos físicos asociados con la situación cotidiana, además de la práctica docente de los estudiantes universitarios de física. Esta investigación tiene como objetivo abordar las principales dificultades en la enseñanzaaprendizaje de estudiantes con necesidades específicas, y lanzar una propuesta para la red escolar, para ayudar a estos estudiantes.

Palabras Clave: Educación, Inclusión, Monitoreo, Sordos, Ciegos

\section{ABSTRACT}

The proposal for inclusion in the Federal Institute of Education, Science and Technology of Rio Grande do Norte - IFRN, Campus Natal Central - CNAT was embraced by the Center for Supporting People with Special Educational Needs - NAPNE, created a monitoring project / research for students with specific needs, seeking to include and assist these students, both in the teaching-learning and social aspects. From a probing test it was observed the difficulties on the part of the students in the exact areas mainly in physics. Soon, in 2018, deaf high school students were invited to participate in the monitoring, and the proposal was opened for students with needs across the Natal-Central campus for the teaching of physics. In 2019, it was proposed to continue the development of the research project in the area of monitoring in which students of the undergraduate Physics Degree, volunteers of NAPNE, volunteered to attend students with deafness and blindness, individually or in pairs, for then develop knowledge about the physical phenomena of nature, using software tools, adapted materials and monitoring in support of regular classes. The results so far are the progression of students' knowledge and autonomy to understand the physical concepts associated with the daily situation, in addition to the teaching practice by undergraduate physics students. This research aims to address the main difficulties in the teaching-learning of students with specific needs, and launch a proposal for the school network, to help these students.

Keywords: Education, Inclusion, Monitoring, Deaf, Blind.

\section{INTRODUÇÃO}

Segundo o Instituto Brasileiro de Geografia e Estatística - IBGE, 2010, no Brasil cerca de 3,4\% da população possui deficiência visual (sendo baixa visão e cegueira) e 1,1\% da população possui deficiência auditiva (sendo baixa audição e surdez). De outro lado, em 2018, o Instituto Federal de Educação Ciência e Tecnologia do Rio Grande do Norte - IFRN, Campus Natal Central - CNAT, recebeu alunos com deficiência auditiva na monitoria proposta pelo Núcleo de Apoio às Pessoas com Necessidades Educativas Especiais - NAPNE que em 2019, no IFRN - CNAT se incrementou com discentes com deficiência visual no ensino superior da licenciatura em física.

Percebia-se claramente as dificuldades desses alunos na aprendizagem e nos conteúdos abordados, principalmente na área da matemática o que inercialmente justificamos com o antecedente de um ensino sem profissionais especializados, e sem auxílio às necessidades 
específicas durante o ensino básico, situação que atualmente ainda exclue pessoas com NEE e consequentemente os exclui do conhecimento. Pode-se perceber que muitas escolas ainda não estão preparadas para receber e abraçar as necessidades dos alunos, no que se refere a estrutura física, assim como a sua estrutura de ensino. E por isso, esta pesquisa implementa-se com o intuito de tornar conhecido, principalmente, as necessidades dos alunos com surdez e cegueira e expandir uma proposta para a rede de ensino.

\section{FUNDAMENTAÇÃO TEÓRICA}

A exclusão social está ligada de forma direta ao conceito sociocultural na qual a sociedade está inserida, nesse contexto o poder aquisitivo interfere no quesito de desigualdade social e consequentemente gera a exclusão, para Bichara:

A vivência de uma situação de desigualdade, de diferenciação social ou de exclusão é a privação das oportunidades e dos benefícios da vida social. Estar excluído é ocupar um lugar inferior ao dos demais, onde há, predominantemente, a falta e a necessidade. (Bichara, 2003, p. 35).

A exclusão diante à desigualdade se é perpetuado para toda a sociedade, assim como afirma Stainback, S \& Stainback, W, (1999):

Quando as escolas são excludentes, o preconceito fica inserido na consciência de muitos alunos quando eles se tornam adultos, o que resulta em um maior conflito social e em uma competição desumana. (STAINBACK, S.; STAINBACK, W., 1999, p.140).

No ponto de vista de Dorizat (2004) os alunos com NEE passa a ser inserido no ambiente acadêmico da mesma forma que os alunos considerados 'comuns", entretanto a forma na qual a instituição acolhe esses alunos não está devidamente qualificada para todas as individualidades.

As mudanças ocorridas pelo o processo de inclusão escolar são consideráveis para os alunos com necessidades educacionais especificas - NEE, como comprova Stainback, S. e Stainback, W. (1999):

O fim gradual das práticas educacionais excludentes do passado proporciona a todos os alunos uma oportunidade igual para terem suas necessidades educacionais satisfeitas dentro da educação regular. $O$ distanciamento da segregação facilita a unificação da educação regular e especial em um sistema único. Apesar dos obstáculos, a expansão do movimento da inclusão, em direção a uma reforma educacional mais ampla, é um sinal visível de que as escolas e a sociedade vão continuar caminhando rumo a práticas cada vez mais inclusivas. (STAINBACK, S.; STAINBACK, W., 1999, p.140).

Abordado o tema de inclusão escolar, a resposta imediata de uma gestão escolar é de 
afirmar a existência de um trabalho aplicado a pessoas com NEE, porém o que no geral pode acontecer é que o discente se adapta a rotina da escola, acredita-se que a inclusão ocorre quando o indivíduo se adequa ao meio, quando na verdade deveria ser o meio quem se adeque ao indivíduo com NEE, tal como afirmado por Pergher:

A inclusão escolar consiste na minimização de todas as barreiras à educação de todos os alunos, sendo um processo de adequação da realidade das escolas à realidade do aluno, visto que não é ele quem deve se adaptar a escola, e sim a escola tomar todas as providências possíveis para o aluno ter garantido seu direito à aprendizagem. (PERGHER apud BOOTH e AINSCOW, 2002).

Mediante essa afirmação Stainback, S. e Stainback, W. indica três componentes necessários para se construir uma escola na qual ocorra uma real inclusão:

Há três componentes práticos interdependentes no ensino inclusivo. O primeiro deles é a rede de apoio, o componente organizacional, que envolve a coordenação de equipes e de indivíduos que apóiam uns aos outros através de conexões formais e informais (Stainback \& Stainback, 1990a, 1990b, 1990c; Villa \& Thousand, 1990). Stone e Collicott (1994) descreveram um sistema bem-sucedido de uma rede de três camadas: grupos de serviço baseados na escola, grupos de serviço baseados no distrito e parcerias com as agências comunitárias. Todos esses grupos funcionam em uma base de apoio mútuo para capacitar o pessoal e os alunos. O segundo componente é a consulta cooperativa e o trabalho em equipe, o componente do procedimento, que envolve indivíduos de várias especialidades trabalhando juntos para planejar e implementar programas para diferentes alunos em ambientes integrados (Harris, 1990; Porter, Wilson, Kelly \& den Otter, 1991; Pugach \& Johnson, 1990; Thousand \& Villa, 1990). O terceiro é a aprendizagem cooperativa, o componente do ensino, que está relacionado à criação de uma atmosfera de aprendizagem em sala de aula em que alunos com vários interesses e habilidades podem atingir o seu potencial (Johnson \& Johnson, 1986; Sapon-Shevin, 1990).(STAINBACK, S.; STAINBACK, W., 1999, p.140).

No ano de 1994, foi elaborado na Conferência Mundial em Salamanca, na Espanha, um documento no qual procurava proporcionar uma base para os sistemas educacionais buscando melhor agregar o movimento de inclusão social. Foi a partir da Conferencia em Salamanca que o assunto de inclusão começou a ser discutida e respeitada, como afirma Santos et al (XXI-?):

\footnotetext{
A partir do documento de 1994, as reflexões sobre as necessidades educacionais especiais dos indivíduos passaram a ser respeitadas, e a situação da acessibilidade começou a ser discutida para um melhor desenvolvimento social e educacional das pessoas com necessidades especiais e de todos os indivíduos desfavorecidos. (Santos et al, XXI-?)
}

No Brasil, apenas na década de 90 começou a implantar-se políticas de inclusão, sendo discutidos os temas de acessibilidade, qualidade no ensino e a inclusão dos deficientes no ensino superior (CARVALHO, 2015). Entretanto, atualmente as políticas de inclusão ainda enfrentam dificuldades e possuem necessidades de ajustes, indicando um grande trajeto a percorrer nas ações que auxiliam as pessoas com deficiência (BORGES, 2011).

Sobre o desenvolvimento das habilidades dos alunos com NEE, Borges afirma, 
O processo de inclusão se preocupa em garantir a todos os alunos, independentemente das suas condições especiais, o mesmo direito com relação à educação e ao atendimento das necessidades especificas, para que possam desenvolver suas habilidades.” (BORGES apud SANTOS et al, 2017).

Para a real efetivação do processo de inclusão é de suma importância que as escolas regulares combatam as atitudes discriminatórias, criando um ambiente propicio e acolhedor para que assim seja alcançado uma educação para todos, conforme a Declaração de Salamanca.

A fim de desenvolver as habilidades na área de ciências da natureza especificamente em física, foram utilizadas a Zona de Desenvolvimento Proximal-ZDP, para SILVA, “A Zona de Desenvolvimento Proximal é a distância entre aquilo que o ser humano consegue fazer sozinho e o que ele consegue desenvolver com a mediação do outro". Para isso, foi utilizado um universo de ações do cotidiano, envolvendo os discentes em uma metodologia que concebesse uma visão crítica, criativa e transformadora do mundo no qual estão inseridos.

Portanto, buscando o auxílio de tutores no ensino de alunos com NEE o processo de ensino-aprendizagem passa a ser significativo, como declara SILVA, "Não é possível aprender e apreender sobre o mundo, sobre as coisas, se não tivermos o outro, ou seja, é necessário que alguém atribua significado sobre as coisas, para que possamos pensar o mundo à nossa volta". (SILVA, 2007, p.12). Para isso ocorrer o monitor serve como mediador da construção do conhecimento, atuando diretamente no potencial em que o aluno com tal individualidade é capaz de alcançar com a assistência de um terceiro. Com diferentes recursos educativos, estratégias de ensino, técnicas e a organização específica para o aluno, passa a ocorrer de fato o ensino-aprendizado, como assegurado no Art. 59 da Lei de Diretrizes e Bases - Lei 9394/96.

Para um melhor ensino-aprendizagem é realizado um trabalho no qual os discentes sintam confiança com o tutor e expressem, sem receio, seus valores, suas opiniões e sentimentos, pois:

Se os professores aceitam os alunos como eles são, permitem que expressem seus sentimentos e atitudes sem condenação ou julgamentos, planejam atividades de aprendizagem com eles e não para eles, criam uma atmosfera de sala de aula relativamente livre de tensões e pressões emocionais, as consequências que se seguem são diferentes daquelas observadas em situações onde essas condições não existem. As consequências, de acordo com as evidências atuais, parecem ser na direção de objetivos democráticos (ROGERS apud GOBBI; MISSEL, 1998, p.27).

Com base no modelo construtivista de Vygotsky e a partir da interação entre os monitores e os alunos - sendo fundamental para a Zona de Desenvolvimento Proximal, é aplicado estratégias pedagógicas adequado para cada tipo de deficiência. A cegueira por sua vez é oferecido materiais na qual é mais utilizado o tato, para Domingues et al (2010): “[...] deficiência requer a utilização de estratégias e de recursos específicos, sendo muito 
importante compreender as implicações pedagógicas dessa condição visual e usar os recursos de acessibilidade adequados no sentido de favorecer uma melhor qualidade de ensino.”.

Também utilizando estratégias nos recursos a serem utilizados com os alunos com deficiência auditiva é buscado não só uma melhor qualidade de ensino como também uma maior interação com os monitores e todo o corpo acadêmico, segundo Santos e Chagas:

\footnotetext{
"A inclusão de surdos deve passar primeiramente pela valorização da qualidade do ensino oferecido e por uma atenção especial à formação dos profissionais que trabalham direta ou indiretamente com esses alunos. A escola, como um todo, deve estar apta para atender as necessidades específicas dos alunos surdos, devendo atentar para que haja uma verdadeira interação entre ouvintes e surdos não estando restrita apenas a uma pequena noção da Libras. [..]". Santos e Chagas (2012, p. 10).
}

As formas de tentar driblar todas as barreiras inseridas no processo de inclusão, vem proporcionando ao aluno com NEE ambientes adequados o que facilita a aprendizagem do aluno. De acordo com Juvêncio (2013):

[...] além da limitação proveniente da deficiência no aluno, esta tende a se tornar uma barreira ao aprendizado quando prejudica a sociabilidade, a interação social, a cultura e a história. O desenvolvimento de recursos de acessibilidade é, antes de qualquer coisa, uma maneira de tentar dirimir as barreiras e proporcionar ao aluno com deficiência os ambientes adequados para a aprendizagem.

\section{METODOLOGIA}

Esta pesquisa é qualitativa e tem por objetivo proporcionar ideias que motivam e melhoram o ensino de física (mas também de outras áreas), para alunos com necessidades especiais específicas, em especial para surdos e cegos.

Além de contribuir com a inclusão desses alunos no campus IFRN Natal - Central, sendo essa uma pesquisa-ação que segundo Elliott (1997), permite superar as lacunas existentes entre a pesquisa educativa e a prática docente, ou seja, entre a teoria e a prática, e os resultados ampliam as capacidades de compreensão dos professores e suas práticas, por isso favorecem amplamente as mudanças. Mas também uma pesquisa aplicada, que busca produzir um conhecimento aplicado no cotidiano, auxiliando em uma situação.

Tendo a educação como campo de exploração de ideias para aplicações no ensino de alunos surdos do ensino médio integrado, e alunos cegos e com baixa visão do ensino médio de licenciatura em física. Os monitores que auxiliam no ensino desses alunos, são licenciandos em física do IFRN Natal - Central que utilizam nas monitorias, quadro branco e pincel, projetor e slides, programas e softwares, materiais e textos adaptados, e materiais de laboratório de física.

As monitorias dos surdos acontecem em salas que os monitores reservam com antecedência, com o auxílio de softwares, materiais concretos, tanto adaptados quanto de laboratório, ou uso de quadro e pincel contando com o conhecimento básico de libras dos monitores. 
De mesmo modo, as monitorias dos alunos cegos acontecem em salas reservadas pelos monitores, e se utiliza de materiais adaptados e concretos criados pelos próprios monitores com o intuito de passar o conhecimento através do tatear (tato) do aluno. Além disso são feitos resumos por áudio e auxílio nas dúvidas dos mesmos pelos monitores.

\section{RESULTADOS E DISCUSSÃO}

É inegável que o ensino de alunos com NEE mudou bastante visto que, foi preciso percorrer um longo caminho para que as pessoas com qualquer tipo de deficiência sejam aceitas na sociedade, e por consequência na escolarização. Antes, a sociedade excluiu e segregou pessoas com tais necessidades, até o século XX, mais precisamente na década de 60 a 70, em que foram integrados à sociedade. Essa integração se dava pela aceitação dessas pessoas, mas elas tinham que se adaptar à sociedade, e no âmbito escolar, os alunos com NEE tinham que ser atendidos apenas na classe especial, essa composta apenas de alunos com NEE. É somente na década de 90 que surge o paradigma da inclusão, que vai enfatizar a igualdade de oportunidades para todos, incluindo pessoas com necessidades especiais, tanto na sociedade quanto na escola (MATOS, 2003). É dito processo de inclusão, pois, além de ser uma novidade para a sociedade, tendo em vista a quantidade de séculos que passamos, a inclusão é algo que deve ser feito dia após dia, com o intuito de incluir essas pessoas em todas as áreas da sociedade.

Entrando no âmbito da educação, a possibilidade de inclusão foi proposta por vários movimentos a favor da inclusão, além disso, foi de suma importância a declaração de Salamanca (1994) que afirma o direito de todas as crianças, incluindo alunos com NEE, à educação independente de gênero. A inclusão dita escolar vem garantir esse direito nas escolas, para que projetos político-pedagógicos sejam implementados com o propósito de dar o direito de acesso, ingresso, e permanência de todos os alunos na escola, independentemente do talento, necessidades específicas, origem socioeconômica ou cultural (STAINBACK, S; STAINBACK, W. 1999).

Porém, mesmo com todo o bom impacto causado pela inclusão, é preciso se atentar para as inadequações que ainda fazem parte de nossa sociedade. $\mathrm{Na}$ área da educação, não é difícil conhecer escolas que ainda não estão aptas a inclusão, tanto na parte da estrutura física como também na área do processo de ensino para àqueles que possuem necessidades específicas. $\mathrm{O}$ fato de muitas escolas não admitirem profissionais capacitados para dar assistência às necessidades de alunos com NEE é consequência de não aceitarem os mesmos como alunos da instituição.

A educação inclusiva não exclui a possibilidade de existir uma educação especial, desde 
que ocorram em paralelo. Inclusive, a educação inclusiva depende da existência de suportes especializados, na formação de profissionais especialistas em diferentes tipos de necessidades especiais e de ensino (BLANCO; GLAT, 2007). Por isso, no Brasil, o Atendimento Educacional Especializado - AEE é obrigatório aos alunos com NEE, sendo ofertado no turno inverso ao da classe comum. O AEE auxilia no processo de ensino aprendizado do aluno com NEE, sendo desenvolvido por um profissional especializado que verifica as barreiras para a aprendizagem e adequa materiais, formas de se trabalhar e ambientes que favoreçam o ensino para o aluno em questão, que será observado pelo educador do ensino regular deste aluno, trabalhando em parceria com o AEE.

Esta pesquisa tem a proposta de levar a monitoria como meio de complementar as aulas e tirar dúvidas desses alunos, buscando trabalhar de forma à auxiliar no conhecimento de uma área especifica da área das ciências (física), e colocá-los em nivelamento aos alunos da mesma turma do ensino regular. Contando com a parceria do professor do ensino comum desses mesmos alunos. É aplicado por monitores alunos da licenciatura em física, de forma que aconteça na própria instituição de ensino dos alunos com NEE, o IFRN Natal - Central. Utilizando o auxílio de materiais adaptados e apropriados para um melhor ensino-aprendizagem deles.

A atuação acontece na área da física e matemática, porém os primeiros alunos monitores foram os alunos de física que se disponibilizaram voluntariamente para este trabalho. A área da física é abordada pois, muitos alunos têm dificuldade nessa matéria, sendo formada por teoria e cálculos matemáticos. Além de experimentos físicos em que muitas vezes são abordados a comparação dos resultados teóricos e o resultado experimental. Isso torna essa disciplina complexa para qualquer aluno.

Para melhor abranger toda essa discussão na área da física, os resultados obtidos no ensino de física dos alunos surdos e cegos na tutoria, será dividida em suas necessidades.

\section{Pessoas surdas}

Os surdos totais são aqueles que tem perda total (ou próximo disso) da audição, já o termo deficiente auditivo é utilizado pela medicina, e pode ser considerado aquele que tem perda parcial da audição, porém muitos surdos não utilizam essa terminologia, e acreditam que vai depender do indivíduo e de como ele se enxerga na comunidade surda. Uma pessoa que é surda não se utiliza da linguagem oral, mas da linguagem corporal, denominada LIBRAS no Brasil.

É a partir da LIBRAS que um surdo se comunica e entende o que querem explicar para 
ele. Por isso, na sala de aula é imprescindível a atuação de um intérprete para traduzir a aula falada na linguagem nativa do professor da escola regular para a linguagem da LIBRAS. Essa linguagem, diferente da língua oral que contêm conectivos, é visual e passada de uma forma direta. Por isso, esses alunos têm uma forma abstrata de pensar, e até de socializar-se.

\section{Surdos do projeto de tutoria}

No começo do projeto/pesquisa, segundo semestre de 2018, os monitores trabalhavam com três surdos do ensino médio auxiliando no contra turno das aulas no IFRN Natal-Central. As aulas eram aplicadas no laboratório de mecânica do curso da física, utilizando-se materiais como: régua, fita métrica, calculadora, entre outros. Além de materiais de matemática, como escala cuisenaire, geoplano, materiais de laboratório como massas de ferro, transferidor, quadro, pincel, softwares entre outros

Figura 1 - Coordenadas cartesianas, na foto os alunos analisam as coordenadas com auxílio de tecnologia assistiva e quadro.
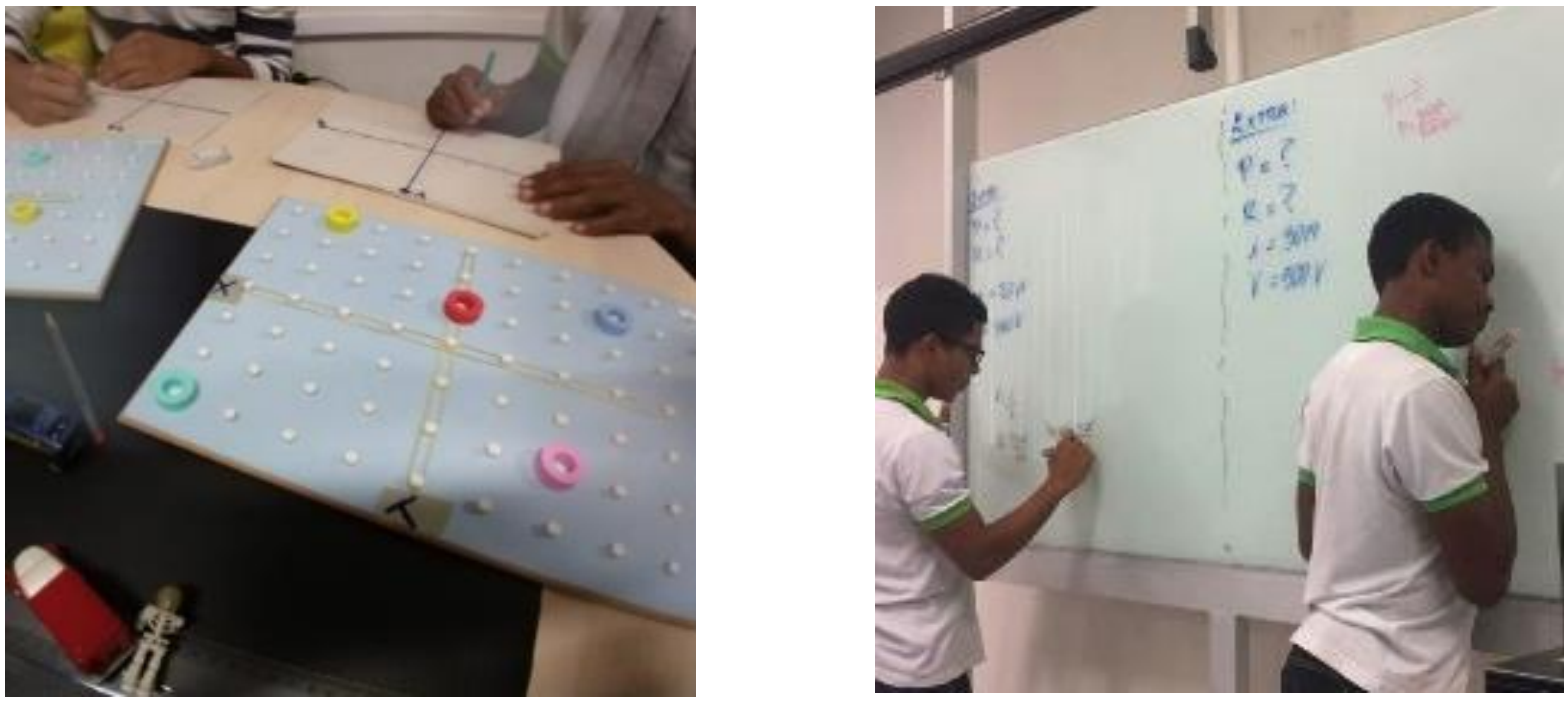

Fonte: Própria (2018,2019).

No começo, os surdos tinham grande dificuldade com matemática básica, e por isso, abordamos os conceitos matemáticos antes de entrar em conceitos físicos. Assuntos que precisavam de noções de tempo, espaço e matemática financeira eram desconhecidos pelos alunos. Isso porque esses alunos não tinham o auxílio de intérpretes no ensino anterior, isso provocou um enorme problema em estudantes que, quando chegavam em sala, eram integrados a turma socialmente, mas excluídos de aprender um novo conhecimento. Apenas no ensino médio integrado do IFRN tiveram auxílio de intérpretes.

A partir das aulas de tutoria em conjunto ao ensino regular em parceria com o intérprete 
em sala de aula e nas tutorias, esses alunos conseguiram aprender conceitos e conhecimentos que antes não eram direcionados a eles. De forma abstrata calcularam a área de quadrados e triângulos utilizando réguas e transferidor para medir ângulos de triângulos e abordar assuntos como teorema de Pitágoras. A tutoria também serviu como um auxílio as aulas de física, depois de ser abordado os conceitos básicos de matemática. Conceitos como velocidade, distância percorrida, aceleração, foram trabalhados de forma abstrata com o auxílio de bonecos, geoplano, e inclusive com o cronômetro correndo ao redor da quadra para calcular velocidade e aceleração.

Figura 02 - Monitoria dos discentes surdos utilizando tecnologias assistivas, questões de velocidade e deslocamento e operações com números inteiros, visando a aprendizagem dos números negativos e

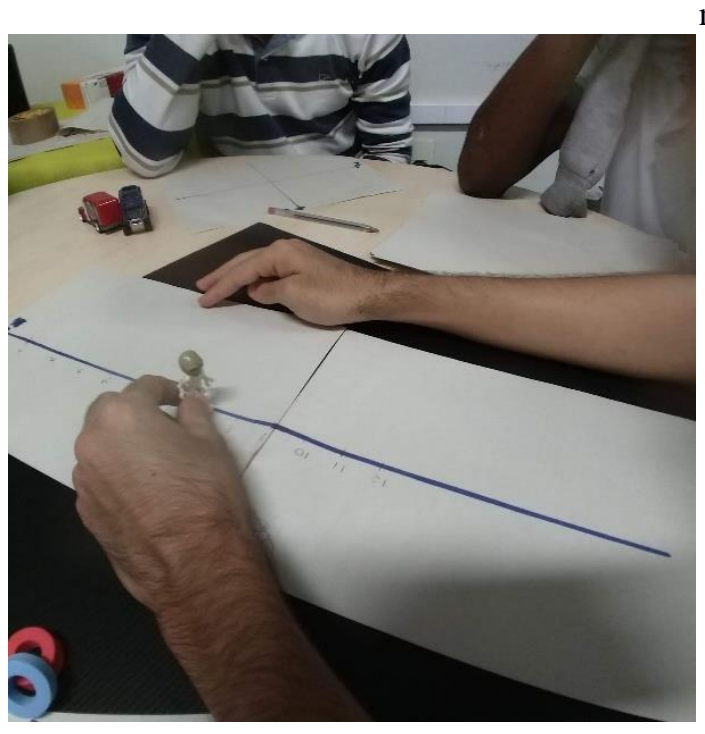
matemática financeira.

Fonte: Própria (2018).

No início de 2019, os surdos conseguiram nivelar e adquirir conhecimentos, dois deles conquistaram a progressão de turma para o segundo ano do ensino médio integrado e continuaram na tutoria contando com o auxílio dos monitores que estão abordando, conteúdos de ondas, óptica, eletromagnetismo e termodinâmica. No mesmo ano, os monitores começaram tutoria com mais três alunos surdos que entraram no IFRN, desenvolvendo os conteúdos do primeiro ano do ensino médio, no quadro e com pincel e utilização das LIBRAS, e se possível utilizando materiais. 
Figura 03 - Monitores aplicando diferentes estratégias para melhor adequar o conteúdo.

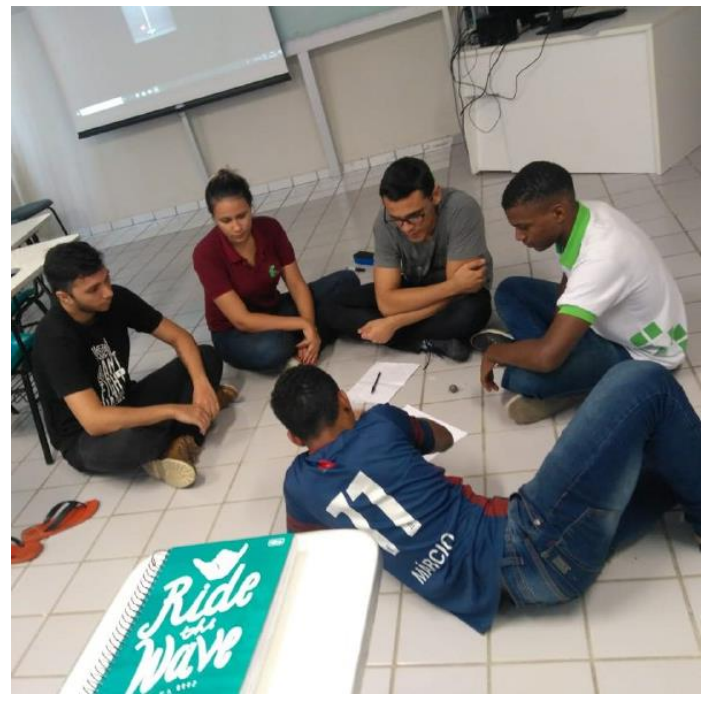

Fonte: Própria (2019).

É importante ressaltar que o método trabalhado com alunos surdos é diferente do método habitual, envolvendo a utilização de objetos concretos e visuais, e por isso algumas adaptações podem ser necessárias para a sala de aula, tanto das aulas regulares quanto das monitorias:

- Posicionar o aluno de forma que possa ver os movimentos do rosto do professor e dos alunos;

- Utilizar materiais visuais e a escrita para que o aluno absorva as informações verbais;

- Utilizando recursos e materiais adaptados;

- Utilizar textos com elementos que favoreçam sua compreensão ligados a língua de sinais;

- Promover a interpretação de textos através de materiais físicos, como pinturas, desenhos;

- Utilizar sempre um meio alternativo de comunicação, como: língua de sinais, linguagem gestual, leitura facial etc.

- Evitar falar de costas, falando sempre o mais claro possível, principalmente para alunos que sabem leitura labial;

- Fornecer uma cópia dos textos antes das aulas;

- Fornecer tempo extra para o aluno responder a provas e testes;

- Evitar ficar de frente a alguma fonte de luz, para não obstruir a visão do aluno;

- Não utilizar o quadro ou material e explicar simultaneamente. 


\section{Pessoas cegas}

É dito cego aquele que perdeu a visão ou está em um estado de quase perda, e deficiente visual aquele que tem problemas de visão, como: miopia, hipermetropia, presbiopia, astigmatismo etc. Esses com deficiência na visão utilizam-se de óculos como um instrumento que auxilia na necessidade que possui. Já o cego, utiliza-se da audição e o tato como meio de entender o mundo a sua volta.

Por isso, na sala de aula é preciso a ajuda do leitor-transcritor, aquele que vai ser os olhos para o aluno cego e ler tudo o que ele precisa saber no quadro e em qualquer folha de atividade, e também transcrever para uma folha tudo o que foi escrito no quadro ou a resposta de algum exercício ou prova.

\section{Pessoas cegas do projeto de tutoria}

No início de 2019, três pessoas cegas entraram no curso de física do ensino superior do IFRN Natal Central. Dois eram totalmente cegos e um com baixa visão. Assim que entraram, a monitoria no ensino de física no contraturno desses alunos foi proposta a eles, e teve o objetivo de ajudar a tirar dúvidas e auxiliar na percepção do conteúdo de forma que eles possam realmente apreender, por meio de objetos e materiais tateados por eles e aulas enviadas por áudio para ouvirem em casa.

Figura 04 - Alunos cegos caminhando pelo campus para obter noções de distância e utilizando materiais adaptados como estratégia de ensino.
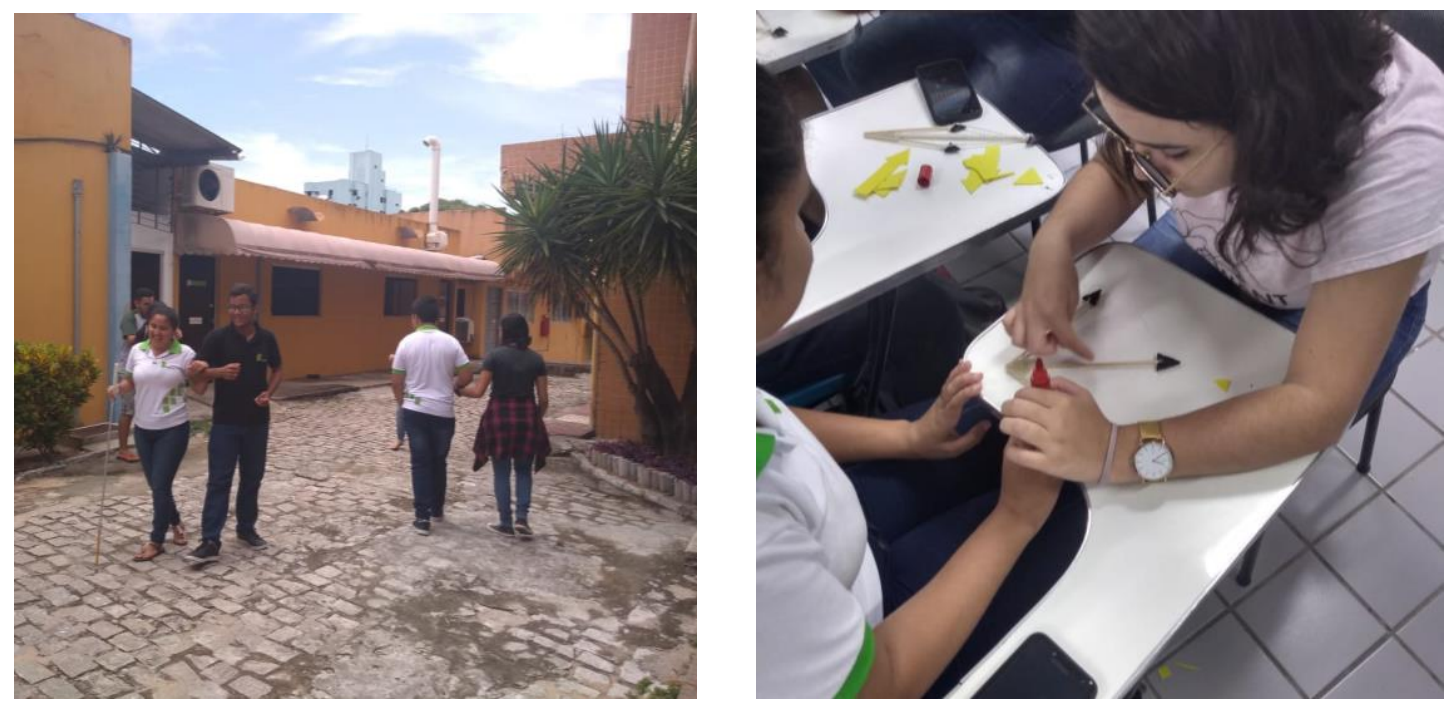

Fonte: Própria (2019).

Inicialmente, eles tinham muita dificuldade pois, no ensino anterior não havia nenhum profissional que os auxiliassem em sala de aula, e não havia monitorias. Apenas frequentavam 
aulas regulares sem nenhum apoio escolar. Mas, depois de participarem das monitorias era perceptível a vontade de aprender de uma das alunas, culminando em sua aprovação na primeira disciplina de física do curso, que no momento está cursando as disciplinas do segundo semestre de 2019.

O trabalho da monitoria com pessoas cegas foi sempre procurar adaptar textos, transformando em áudios, e adaptar materiais, para serem tateados pelos alunos na busca de um melhor entendimento do assunto, como foi feito com o assunto de vetores, velocidade, entre outros, abordados em coordenadas cartesianas.

Figura 05 - Discentes com deficiência visual em monitoria sobre vetores.
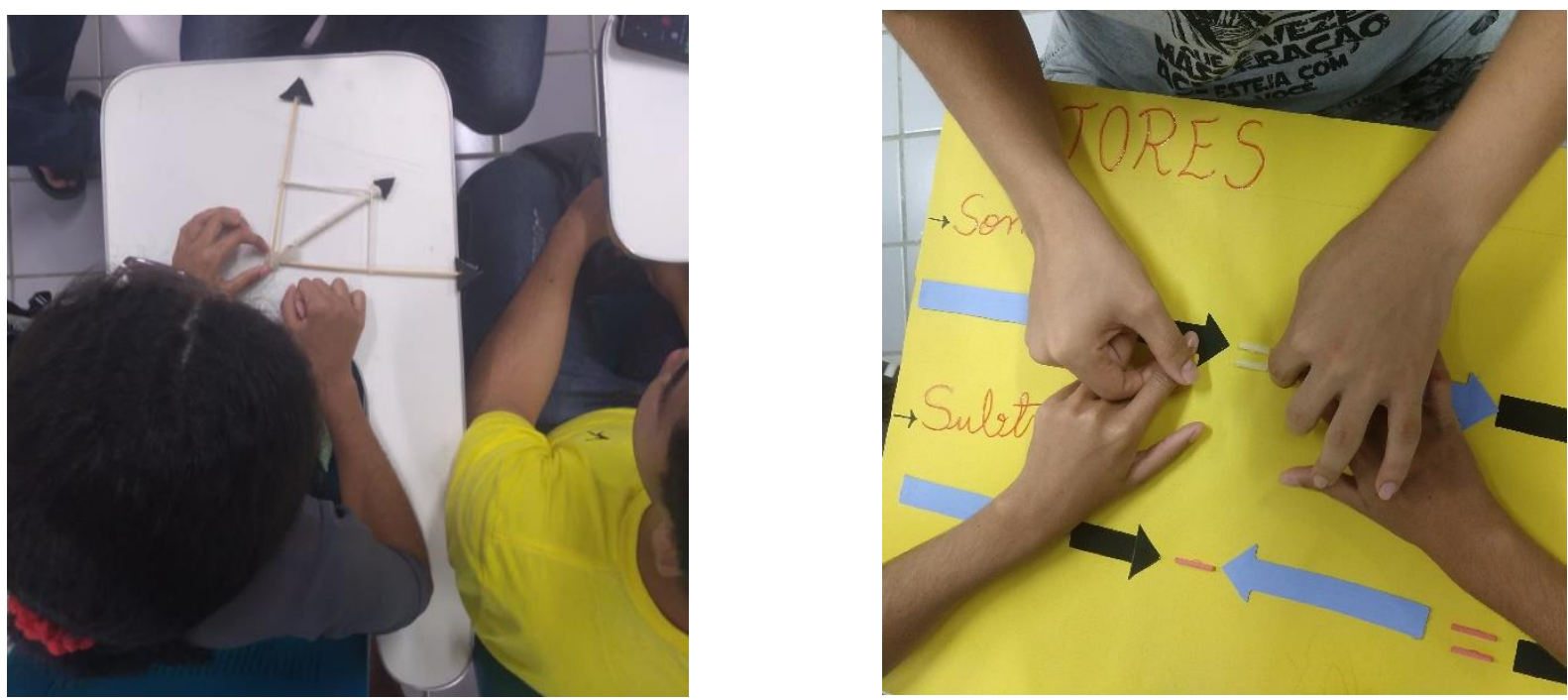

Fonte: Própria (2019).

Portanto, é possível observar que materiais adaptados e áudios são valiosos no ensino a pessoas cegas. Ainda mais com o auxílio do braille, um sistema de escrita tátil, porém não são todos os que compreendem o braille, apenas um dos três alunos era familiarizado com o braille.

A forma de agir em sala de aula para o professor ou monitor é diferente quando na classe existe alunos com cegueira. Levar em conta algumas orientações durante a sala de aula auxiliam os alunos com tais necessidades e é importante para o processo de ensino-aprendizagem deles.

- Posicionar o aluno para favorecer a audição dele na sala de aula;

- Facilitar a locomoção do aluno na sala de aula, para uma maior independência dele, e evitar acidentes;

- Explicar oralmente de forma detalhada todo o material e desenho visual utilizado em sala;

- Oferecer suporte instrucional, físico e verbal para que o aluno possua maior locomoção, referente a orientação espacial, podendo ser oferecida também pelos 
colegas;

- Aumentar o tempo disponibilizado para a realização de atividades e provas;

- Ajudar, apenas, no que for necessário ao aluno;

- Ter um comportamento natural diante do aluno, sem expressar qualquer superproteção ou indiferença;

\section{CONCLUSÕES}

Atualmente, os monitores do projeto estão em tutoria com os surdos do segundo ano e os do primeiro, além dos cegos do ensino superior de física. A evolução dos alunos surdos do segundo ano foi gratificante, pois, passaram de alunos que não entendiam conceitos básicos de matemática, e conceitos do cotidiano como financeiro, horas e distância, para alunos que melhor entendiam esses conceitos e aprendiam novos conceitos que os próprios colegas de sala não tinham conhecimento, de forma a causar um melhor nivelamento com a turma. Isso foi possível principalmente pelo desempenho e vontade de aprender desses alunos.

Já na tutoria com os cegos, uma aluna dos três se destacou e foi aprovada na disciplina de pré-cálculo e elementos de física, sendo essas fundamentais para o andamento do curso. Mais uma vez, isso apenas foi possível pelo esforço e vontade de aprender da aluna, que se dedicou as aulas regulares e as tutorias. Dito isso, é indispensável que o aluno, com ou sem necessidades, possua vontade e dedicação aos estudos para que os conhecimentos sejam realmente concretizados.

Esse processo na vida dos alunos com NEE é possível desde que sejam auxiliados em suas necessidades básicas, pois, todos os alunos são abertos ao conhecimento, afinal, somos seres racionais. E por tudo que foi abordado até aqui, é sugerido o desenvolvimento do trabalho de monitoria como uma proposta de ensino para ambas redes, estaduais e privadas, para que esses alunos também tenham direito ao conhecimento e que nenhuma dificuldade ou necessidade deles se tornem uma barreira na metodologia de ensino, no processo de ensinoaprendizagem e no processo de inclusão de todos os alunos ao ensino.

\section{REFERÊNCIAS}

BOOTH, T.; AINSCOW, M. Index For Inclusion. Portugal: Associação Cidadãos do Mundo, 2002.

Bichara TAC. Exclusão e informalidade: um estudo sobre o lugar social dos vendedores ambulantes do centro histórico de Quito - Equador [dissertação de mestrado]. São Paulo: Pontifícia Universidade Católica de São Paulo; 2003. 
BRASIL. [Constituição (1996)]. Leis de Diretrizes e Bases - LDB. [S. l.: s. n.], 1996.

BORGES, Maria Aparecida. A INCLUSÃO DE ALUNOS COM DEFICIÊNCIA EM CURSOS PRESENCIAIS DE GRADUAÇÃO DA UNIVERSIDADE FEDERAL DE JUIZ DE FORA. 2011. Dissertação (Pós-Graduação em Educação) - Faculdade de Ciências e Tecnologia da Universidade Estadual Paulista, [S. l.], 2011.

Dorizat, A. (2004). Educação De Surdos No Ensino Regular: Inclusão Ou Segregação? Revista do Centro de Educação Especial, n.24, 2004. https://periodicos.ufsm.br/educacaoespecial/article/view/4921/2955.

DEClARAÇÃO DE SALAMANCA: Sobre Princípios, Políticas e Práticas na Área das Necessidades Educativas Especiais, 1994, Salamanca-Espanha.

DIAS, Rayala Santos et al.. Percepção dos Monitores para Alunos com Deficiência Visual nos Cursos de Administração e Ciências Contábeis, [s. l.], 1 dez. 2017.

FRIAS, Elzabel Maria; MENEZES, Maria Christine. INCLUSÃO ESCOLAR DO ALUNO COM NECESSIDADES EDUCACIONAIS ESPECIAIS: contribuições ao professor do Ensino Regular. Inclusão, [s. l.], XXI-?.

Stainback, W., \& Stainback, S. (1999). Inclusão Um Guia Para Educadores. PORTO ALEGRE: ARTMED.

Santos, Alex Et Al. Edueducação Inclusiva E A Declaração De Salamancacação Inclusiva E A Declaração De Salamanca. Educação Inclusiva E A Declaração De Salamanca, [S. L.], Xxi Xxi-?. Disponível Em: Https://Portal.Fslf.Edu.Br/Wp-Content/Uploads/2016/12/Tcc_07.Pdf. Acesso Em: 22 Out. 2019.

SILVA, Daniela Regina da. Psicologia da Educação e Aprendizagem. Associação Educacional Leonardo da Vinci (ASSELVI). - Indaial: Ed. ASSELVI, 2006.

SANTOS, Maria Viviane dos; CHAGAS, Yasodaria Maria Mota. Educação inclusiva para surdos: desafios e perspectivas. IN: Editora Realize, Campina Grande, 2012. 